\title{
The Domestication of Global XPS at Local Production Sites
}

\author{
Hanne O. Finnestrand and Kristoffer Magerøy \\ SINTEF Technology and Society, Industrial Management, Trondheim, Norway \\ \{hanne.o.finnestrand, kristoffer.mageroy\} @sintef.no
}

\begin{abstract}
Inspired by the success created by Toyota and its Toyota Production System (TPS), many large multinational corporations have developed their own company-specific production systems (XPSs). However, it varies to what degree local production sites have made use of the global corporate's PS and in what way it has had any effect on the local site's work practice. In this paper we discuss the technical, social, and cultural factors of the implementation of XPS through the lenses of domestication theory. This study indicates that a rational implementation of global XPS' is all practical, symbolic, and cognitive, and that development of new technology as well as production systems is a multi-sited process. Hence, corporates as well as local sites need to take account for how local managers and employees are involved in the implementation process.
\end{abstract}

Keywords: XPS, domestication, case study, operations management.

\section{Introduction}

Inspired by the success created and maintained by Toyota and its Toyota Production System (TPS), many large multinational corporations have developed their own company-specific production systems (XPSs) [1]. Examples are Boing Production System, Electrolux Manufacturing System, Elkem Business System and Volvo Production System. While 'PS' is an abbreviation for 'production system' or something similar (e.g. TPS), the ' $\mathrm{X}$ ' stands for the company name.

The amount of foreign investments in the Norwegian industry have grown substantially the last decade, and today foreign owned firms constitute $30 \%$ of the employment in the industry [2]. In numbers it has nearly been a doubling from just above 800 companies in 2003 to nearly 1600 companies in 2010. Combined with the growing numbers of XPSs, this leads to an increase of Norwegian manufacturing firms facing the challenge of implementing such a system. However, it varies to what degree local production sites have made use of the corporates' production systems and in what way it has had any effect on the local sites' work practice. Hence, an emerging and important question is: How can we understand the process of implementing global XPS in local production companies? In order to study this, we have made use of domestication theory and have addressed this through a multiple case-study of three Norwegian manufacturing companies owned by global corporates. 
Domestication - A Theoretical Introduction. In order to understand the technical, social, and cultural factors [3] of the implementation of XPS, we make use of domestication theory. Domestication in a figurative sense is to make something taken from an outside world applicable, meaningful and useful to a local world. The concept was taken up by the field of science and technology studies to describe how innovations and new technologies are appropriated by users [4]. Domestication theory holds that technological adoption is an interactive process, opposed to a view where technology forces culture and organization to be reshaped - also called technology determinism.

Within studies of sociology of technology, domestication is a concept developed to describe and analyse processes of technology acceptance, rejection and use [5]. In this paradigm, technology is usually understood as a particular artefact such as domestication of the car [6], domestication of multimedia technologies [7], or the domestication of the mobile phone [8]. An XPS is not one specific technology or artefact. It is rather a bundle of technologies and practices, and although several companies have made efforts in designing their own XPSs, there is still a tight relationship between different XPSs today and the technical understanding of the TPS and lean production [1].

When we chose to analyse the implementation processes of XPSs within this framework, it is because domestication theory goes longer than contingency theory [9] or organizational learning theories [10] in including the social dimensions of implementation processes. More specifically, domestication theory focuses on the construction of meaning; hence Sørensen et al. [11] argue that to domesticate technology means to negotiate its meaning and practice in a dynamic, interactive manner. They claim that this negotiation implies that technologies as well as social relations are transformed. Based on this, Sørensen et al. [11] developed three main, generic sets of dimensions when analysing the implementation of technology.

The first dimension is the construction of a set of practices related to the new technology. This could mean routines of using the technology, but also the establishment and development of institutions to support and regulate this. Second, the construction of meaning of the technology, including the role the technology eventually could play in relation to the identities of the actors involved, and finally, the cognitive processes related to learning of practice as well as meaning [8], [11]. The latter dimension requires that the practice or system is integrated into social practice of action. We will make use of these three features when analysing the empirical material.

\section{Methodology}

We have carried out instrumental case studies in three different manufacturing companies in order to develop an understanding of domestication of XPS. An instrumental case study provides insight into a particular issue, redraw generalizations, or build theory [12]. As with most instrumental case studies, the research team wanted to build new theory by building on and testing existing theory - namely how domestication theory known from science and technology studies [4] informs the implementation of a company specific production system, also called XPS. The multiple case study design enables us to reveal complementary aspects of the phenomenon. 
The research team has made individual case reports for all three companies based on mainly three data sources: (1) semi-structural interviews with key personnel such as production managers, shop stewards, HR-managers, and blue collar operators; (2) informal conversations with operators when visiting the production; and (3) available information on the companies' web pages and other written materials developed mainly in order to promote the company and the company group.

\section{Case Studies}

The presentation of each case study starts with a short introduction to the company, followed by a summary of the most relevant findings. In order to anonymize the companies, we have named them company $\mathrm{A}, \mathrm{B}$, and $\mathrm{C}$.

Company A. Company A has about 115 employees and develops and produces advanced tools for a world-wide market within mechanical and petroleum industry. Some years ago the company was bought by its exclusive sale channel; a hightechnology, engineering group with advanced products and representations in more than 130 countries. First, this change did not cause any implementation of an XPS, however later the corporate launched a common improvement program.

The company has gone through many changes over the last years, also before becoming part of the corporate. For many years they invested in organizational factors such as establishment of autonomous teams, improved communication within and between production teams, some of the lean principles, and widespread unionmanagement cooperation. The way company A has chosen to involve both the union and production workers as a development partner is quite unique. Their organizational approach has led to a number of extensive development projects with the aim to decentralize decision making to the shop floor in order to be more efficient and flexible. Clearly, the corporate bought a flexible organization capable and used to change.

Also, just before company A merged with the corporate, the company moved into totally new premises. When moving from dark and crowded premises at the old production site, the production workers could suddenly enjoy panoramic view through enormous windows and eat delicious lunch in the company's cafeteria.

In the beginning, both employees and managers found the transition of ownership to be quite smooth. The difference was in most cases described as positive. The managers claimed that the corporate offers a world market for their core product and increases the general robustness of the plant. The employees emphasized that being part of a larger corporate gives them the opportunity to work at other facilities.

Also, in the first two-three years after the transition company A was allowed to operate pretty much as they wanted - or at least the same way as prior to the acquisition. The HR-manager described the autonomy and freedom like this: "I went to a crash course at the [corporate] in 2009 where we went through the HR-practices at [corporate]. They advised us to make use of those things we liked. They had extensive experience and many good work practices, but we didn't have to copy everything". However, later on this changed quite a lot when the company group decided to 
implement a corporate production system and we received the following e-mail from the production manager: "We will increase the speed of Lean production implementation; this will be done through a global [corporate] production system". The HRmanager explained that she experienced much more standardization within the corporate through this process and now everything had to be related to the corporate's visions. Also, because she had to follow up all the new systems, and even participate in developing them, she felt that she was not as available in the production area as before. She said: "the ambition is to be more available for the employees, but in practice I'm not".

Company B. Company B is a first tier supplier to the global aviation industry, manufacturing highly complex engine products and employs approximately 600 people. As the company has been introduced to a new XPS twice the last decade, this case study provides interesting findings in that respect. The last change was a result of shifting ownership, which also led to increased attention from the head quarter as the company is now part of a major business area within the corporate, in opposite to being part of a business area only constituting a few percent of the total activity.

When introduced to the first XPS, the company experienced that they did not get any clear advice on how and where to start the implementation process. However, they ended up with a quick fix implementation upfront due to a scheduled assessment. The result was that the assessment got a lot more attention than the long term continuous work improvement. The former COO named this way of working as "a Norwegian manufacturing culture - one based on quick fixes". This working culture can be further explained as a task force of engineers moving continuously around in the factory to solve present challenges regarding quality, delivery, etc.

Another visible characteristic of the first attempt was the lack of commitment among leaders. They did not oppose it, but could indisputable been more supportive. It is reasonable to believe that the lack of commitment is in coherence to the little focus put on training. Only a couple of white-collar employees were sent to the corporate academy. In contrast, the implementation of the second XPS involved an extensive training program embracing everyone within the factory and starting with the top management. The program was mandatory and ended with an evaluation focused on productivity. Increased training has resulted in a management team more dedicated to lean than previously. In addition, each site in the corporate needs to assign one continuous improvement leader, providing even more focus and leadership.

As a consequence of the increased focus at productivity, there are now much higher expectations to short-term results. One manager shares his concern: "We have an increased focus on on-time delivery and details regarding flow, quality etc., this is to such an extent that I'm afraid it overruns the need for also maintaining a long term focus". He experiences an anglo-american style of leadership within the corporate, and explains that "it is taken for granted that manager at the top has detailed insight into everything". This is quite opposite to the Scandinavian management practice.

Company $\mathrm{C}$. Company $\mathrm{C}$ has recently been in a situation very much like to company $\mathrm{B}$, as a change of ownership have led to the introduction of a new XPS. The company 
counts around 550 employees and operates in the automotive industry, now as a part of a global division within that field.

A couple of years after introducing the new XPS, company $\mathrm{C}$ experienced that the implementation varied extensively among departments. People in many departments did not feel a belonging to the lean based regime and some related to it as one specific tool, e.g. 5S, the visual boards or even cleaning. "For many of us out here, the corporate system is equal with cleaning" one shop-floor worker commented. The company therefore developed a roadmap for further implementation to secure a more standardized way, and many employees have recently gone through a course. While interviewees holding administrative or support positions regard the course valuable, operators regard it less valuable and say they lack follow-up and do not clearly see how to utilize their new knowledge into their daily work. One respondent puts it this way: "The course has little to do with our everyday work. It would be better if we looked upon and focused at what we do daily."

Not only do the employees struggle with getting a grasp of the content of the new XPS, they are also struggling with seeing the differences compared to the previous, and more self-developed operating system. One experienced worker comments: "To my understanding it is pretty much the same. It just changes name from year to year."

Another issue that appeared through the interviews was management involvement. Shop floor workers have experienced less commitment among team leaders and top managers than before introducing the latest XPS. One comments that "they [managers] must be out here in the production and look at what we do. [...] it is important that they [managers] are visible in the production from time to time".

\section{Discussion}

Routines. Introduced to a new XPS, companies need new practices, routines and institutions to domesticate the system effectively. Basically, the corporate system must be acquired and placed in the company [11]. As an XPS normally contains a vast amount of principles, tools and techniques, the local production unit "receives" a large package of such elements when introduced to an XPS. However, as the case studies show, both company $\mathrm{B}$ and $\mathrm{C}$ have received this package without a following guideline or a schedule for how to grasp it. In company B this resulted in a shallow implementation only due to some assessments, while in company $\mathrm{C}$ the degree of implementation varied extensively among departments leading them to make their own roadmap for further work. Such a roadmap would probably have been the solution for company B as well, if they were not introduced to a new XPS that early.

Furthermore, the findings reveal that the commitment to the previous selfdeveloped operating system in company $\mathrm{C}$ was higher than the commitment to the [corporate] operating system. A locally developed roadmap for further implementation will probably help on this, but the effects still remains to be observed. The diverging perception among employees regarding the recently given courses indicates that the implementation process needs to be adapted even at a department level. All together this shows the importance of local adjustments and adaptation. 
Construction of Meaning. Leaning on domestication theory, the actors that must relate to the XPS usually negotiate the meaning of it and practice in a dynamic, interactive manner. This negotiation implies that the XPS or work systems, as well as social relations are transformed. People read their previous experiences and agendas into new experiences, and the way they talk about it, use it or even misuse it influences the character of the XPS. In other words, the cultural appropriation of the XPS in a local setting is a multidimensional process. We see interesting and informing examples of this process in our cases. In company A, the transition from local own company with its own system to the global corporate system was described as "smooth" by the local managers. It is likely that their freedom and permission to choose practices from the corporate's "tool box" explains this quite seamless merging. However, it is not unlikely that the positive experience and attitude toward the takeover was more a result of new facilities. As one of the production workers said: "We moved right before we became part of [corporate], and those things we were negative towards before was the facilities at the old place. The new place was like a dream". She continues by saying: "It is difficult to say what's a result of what; the new facility or being part of [the corporate]". This illustrates well how seemingly random events have great influence on well-planned strategies - events that can turn plans and strategies in wanted directions or in undesirable directions just because the local company with its employees ascribe certain meaning to the corporate's new strategy.

The construction of meaning is also evident in company C. For instance, it varied to what degree the different departments in the company had made use of the XPS although they were actually offered the same XPS. Of course, the implementation phase in itself is important here; employees who do not have any or limited knowledge of the XPS will not be able to make use of the tools and work forms. However, this doesn't seem to be the case with company $\mathrm{C}$ as the employees had experienced with an earlier XPS. But the previous experiences influence how the company see or understand the new XPS, and in this case primarily two practices of action are evident. First how the XPS, as based on lean manufacturing, is interpreted as a collection of tools such as $5 \mathrm{~S}$ only, and responded to accordingly, and second that the employees interpret it as "pretty much the same" and therefore continue the same way as before. The employees lack of ownership and ignorance of the XPS both undermine it as a useful system and in some cases turns it into something it was not meant to be by the designers, such as a "corporate system equal with cleaning" or local practices just with a different name.

Learning of Practice. Domestication is both pragmatic and a potential issue of conflict. New technology and "know-how" must be domesticated in order to be integrated into local culture, but not all new technology and work forms are domesticated, and different people domesticate different kinds of knowledge and technology [11]. Conflicts arising from domestication may be related to different local interests and roles such as gender, age, and managers versus subordinates. Furthermore, conflicts may be related to the relationship between the XPS designers on the one hand and the local actors' creativity and ability to make use of the new system on the other. The implementation and use of the XPS is understood in relation to the company's social 
practice of action or culture such as how the company carries out leadership, their values, and company specific "do and don'ts". These may or may not be explicit and articulated by the managers and the employees. In other words, in what way the XPS eventually is embedded in the local site's social practice of action is dependent on how well it fits with the actors' self-understanding and culture.

In both company $\mathrm{A}$ and $\mathrm{B}$, potential conflicts in the domestication process seem to be ascribed in what the companies describe as a Scandinavian work form. In company $\mathrm{B}$, the corporate's management style with "increased focus on on-time delivery and everyday details", may fit badly with the local company's self-understanding as highly autonomous on all levels. The same is valid for company A which in addition to an autonomous work force has invested a lot of time, effort and pride in involving both union and production workers as development partners. It is possible that the XPS must be adapted to this social practice of action or that the local enterprise ascribes the XPS new meaning previously described as construction of meaning. In any case, the domestication of XPS will not leave it unchanged, and it is reasonable that the local company with its employees will make use of it differently as a result of the company's routines and institutions. Furthermore, such will affect how the users interpret the new system and give new meaning or re-construct it, and finally how well the XPS fit with the users' self-understanding, culture, or social practice of action.

\section{$5 \quad$ Implications}

In this paper we have made use of domestication theory in order to understand the technical, social, and cultural factors regarding the implementation of XPSs in three different production companies. Etymologically speaking, domestication is related to the home, the domestic setting. However, we have used the word as an analytical concept in order to bring new understanding into the implementation process of new work- and production systems designed by somebody who is not the end user of the system. There is however some differences between the domestication of technology in a broader sense at home and in the work place. The implementation of XPSs in companies are usually acquired by managers and support functions in the corporate in order to achieve some goals [1], and even if the process of implementation may not be as rational as many managers and consultants want it to be, managers are usually able to influence the outcome by controlling the information and training offered to employees [11].

In line with theory and empirical work on domestication of technology and the analysis of the three cases in this paper, we will emphasize particularly three implications when implementing global XPSs in companies. First, this study indicates that a rational implementation is not solely an instrumental action. The implementation phase is practical, symbolic, and cognitive. Second, in many cases the local use of an XPS is embedded in an asymmetric relationship between the assumed expertise of its designers and the assumed non-expertise of its users. In other words, there exists an idea of correct and incorrect usage that is predefined by the designers and the corporate. In principle, users are supposed to acquire knowledge from the designer in order 
to be able to use the XPS in the correct manner. Domestication theory represented by Sørensen et al [11] confronts this linear understanding of design and implementation and stress that the end product is designed through a multi-sited process.

Finally, because an implementation process is all practical, symbolic, and cognitive, and because development of new technology as well as production systems is a multi-sited process, corporates as well as local sites need to take account for how local managers and employees are involved in the implementation process. One way of achieving this could be by making the multi-sited process explicit and involve employees and unions early on in developing a roadmap and a training program specific for the local production site. Hence the effects of such could be of interest to further research.

\section{References}

1. Netland, T.H.: Exploring the phenomenon of company-specific production systems: Onebest-way or own-best-way? International Journal of Production Research 51, 1084-1097 (2012)

2. Ulstein, H., Günfeld, L.A., Ekrann, G.: Indutrielt eierskap i Norge. Menon Business Economics (11) (2012)

3. Bakardjieva, M., Smith, R.: The Internet in Everyday Life: Computer Networking from the Standpoint of the Domestic User. New Media \& Society 3, 67-83 (2001)

4. Hirsch, E., Silverstone, R.: Introduction. In: Hirsch, E., Silverstone, R. (eds.) Consuming Technologies: Media and Information in Domestic Spaces. Routledge, London (1992)

5. Berker, T., Hartmann, M., Punie, Y., Ward, K.: Introduction. In: Berker, T., Hartmann, M., Punie, Y., Ward, K. (eds.) Domestication of Media and Technology, McGraw-Hill International (2006)

6. Østby, P.: Flukten fra Detroit: Bilens integrasjon i det norske samfunnet. Universitetet i Trondheim. Senter for teknologi og samfunn (1995)

7. Brosveet, J., Sørensen, K.H.: Fishing for fun and profit? National domestication of multimedia: the case of Norway. The Information Society 16, 263-276 (2000)

8. Sørensen, K.: Domestication: the enactment of technology. In: Berker, T., Hartmann, M., Punie, Y., Ward, K. (eds.) Domestication of Media and Technology. McGraw-Hill International (2006)

9. Swink, M., Nair, A.: Capturing the competitive advantages of AMT: Designmanufacturing integration as a complementary asset. Journal of Operations Management 25, 736-754 (2007)

10. Argyris, C., Schön, D.: Organizational Learning: A theory of action perspective. AddisonWesley, Reading (1978)

11. Sørensen, K., Aune, M., Hatling, M.: Against linearity - On the Cultural Appropriation of Science and Technology. In: Dierkes, M., Grote, C. (eds.) Between Understanding and Trust: The Public, Science and Technology, Harwood, Amsterdam (2000)

12. Stake, R.E.: Multiple Case Study Analysis. The Guilford Press, New York (2005) 